\title{
Assessment of spatial relationship between land surface temperature and landuse/cover retrieval from multi-temporal remote sensing data in South Karkheh Sub-basin, Iran
}

\begin{abstract}
Land surface temperature (LST) is a required input data for modeling in climatological, hydrological, agricultural, and change detection studies. In the current study, remotely sensed thermal infrared data were applied to assess LST in south Karkheh sub-basin, Iran. This research deals with the extraction of LST and land surface emissivity (LSE) and the relationship between vegetation abundance using Landsat 5 TM and Landsat 7 ETM+ for October 1998 and 2002 over the studied area. The landuse/land cover (LULC) map was derived by using maximum likelihood classifier. The variety of LSE was investigated and extracted on the basis of NDVI threshold method, as well as the Plank equation was used to derive LST over the study region. The relationship between LST and different LULC is determined by zonal GIS and regression analysis. The results illustrate that the emissivity lies in the range of 0.860-0.992 and 0.855-0.992 in 1998 and 2002, respectively. The maximum value of LSE equal to $\sim 0.99$ was observed over the dense vegetation, while the minimum LSE value equal to $\sim 0.880$ was found over the sand dune. LST and NDVI analysis exhibits a strong inverse correlation except over water bodies. The strongest coefficient correlation was found over wetland $(-0.76$ and $\mathrm{R} 2=0.78)$.
\end{abstract}

Keyword: Land surface temperature (LST); Normalized difference vegetation index (NDVI); Land surface emissivity (LSE); Remote sensing; GIS 